\title{
Australia's role in promoting and supporting tuberculosis control in the Western Pacific Region
}

\author{
Kerrie A. Shaw \\ South Eastern Sydney Local Health District (Northern Sector) \\ and St Vincent's Hospital (formerly Australian Respiratory \\ Council, Sydney) \\ Email:Kerrie.Shaw2@sesiahs.health.nsw.gov.au
}

\begin{abstract}
Twenty-one percent of the world's tuberculosis cases are found in the Western Pacific Region. The region has demonstrated a lower rate of decline in incidence than the regions of Africa, the Americas and Europe. Issues around drug resistance, human immunodeficiency virus and diabetes impact on the burden of tuberculosis disease in the Western Pacific Region. Australia has exhibited a low and relatively stable tuberculosis incidence rate but has not progressed toward the desired international goal for tuberculosis elimination ( $<1$ case per million population). The pathogenesis and transmission of tuberculosis make it difficult to achieve elimination within a geographically defined area. These aspects of disease control are amplified by globalisation and Australia's increasing economic and strategic engagement within the Western Pacific Region and South-East Asia. Promoting and supporting tuberculosis control within the Western Pacific Region provides an opportunity for Australia to maintain its low tuberculosis incidence rate and progress toward elimination.
\end{abstract}

There has been major progress in reducing tuberculosis (TB) incidence and deaths worldwide since the World Health Organization (WHO) declared TB a global emergency in 1993, yet the global situation continues to be described as a TB epidemic. ${ }^{1}$

Significantly for Australia, 60\% of the world's TB cases are found in the Asia Pacific, which constitutes the two geographical areas described by WHO as the Western Pacific Region (WPR) (which includes Australia) and the South-East Asia Region (SEAR) (Figure 1). Both regions demonstrated lower rates of decline in TB incidence from 2010 to 2011 than the regions of Africa, the Americas and Europe $\left(2.3 \%, 2.0 \%, 3.1 \%, 3.8 \%, 8.5 \%\right.$ respectively). ${ }^{1}$ As demonstrated by national data, the profile of TB in Australia is affected by the burden of TB in these two regions, with approximately $73 \%$ of $\mathrm{TB}$ cases notified in Australia being born in the WPR $(30 \%)$ or the SEAR $(43 \%) .{ }^{1-3}$ This paper will outline the profile of TB in the WPR, Australia's current role in regional* TB control and the importance of Australia's strategic engagement in the WPR in sustaining an effective local TB control program.

\section{The Western Pacific Region}

The WPR (Figure 2) is home to nearly one-third of the world's population (approximately 1.8 billion people). It comprises some 37 countries and is recognised as one of the most diverse of the WHO regions, containing highly developed countries (e.g. Australia, Japan, New Zealand, the Republic of Korea and Singapore), some of the world's least developed countries (e.g. Cambodia, Kiribati, Samoa, Solomon Islands and Vanuatu) and fast growing economies such as China and Viet Nam. Large variations in population size exist between countries of the WPR, with over 1 billion people residing in China and only 52 people living in the Pitcairn Islands. Importantly, the WPR does not include Indonesia, Timor-Leste, India or Bangladesh, which contribute significantly to the burden of TB disease in Australia; ${ }^{4}$ these countries are within the SEAR, which is not the subject of this paper.

\section{Tuberculosis control in the WPR}

WHO estimates that in 2011 there were approximately 1.7 million incident cases of TB in the WPR. ${ }^{1}$ The WPR contains four of the 22 high TB incidence countries that have received particular attention at the global level since 2000: Cambodia, China, the Philippines and Viet Nam account for $17 \%$ of $\mathrm{TB}$ incident cases worldwide, and almost $93 \%$ of the TB incident cases in the WPR. ${ }^{1}$ It is estimated that $28 \%$ of global multidrug-resistant TB (MDR-TB) cases are within the WPR; China, the Philippines and Viet Nam account for the majority of

*Unless otherwise indicated, the terms 'regional' and 'region' refer to the WPR. 


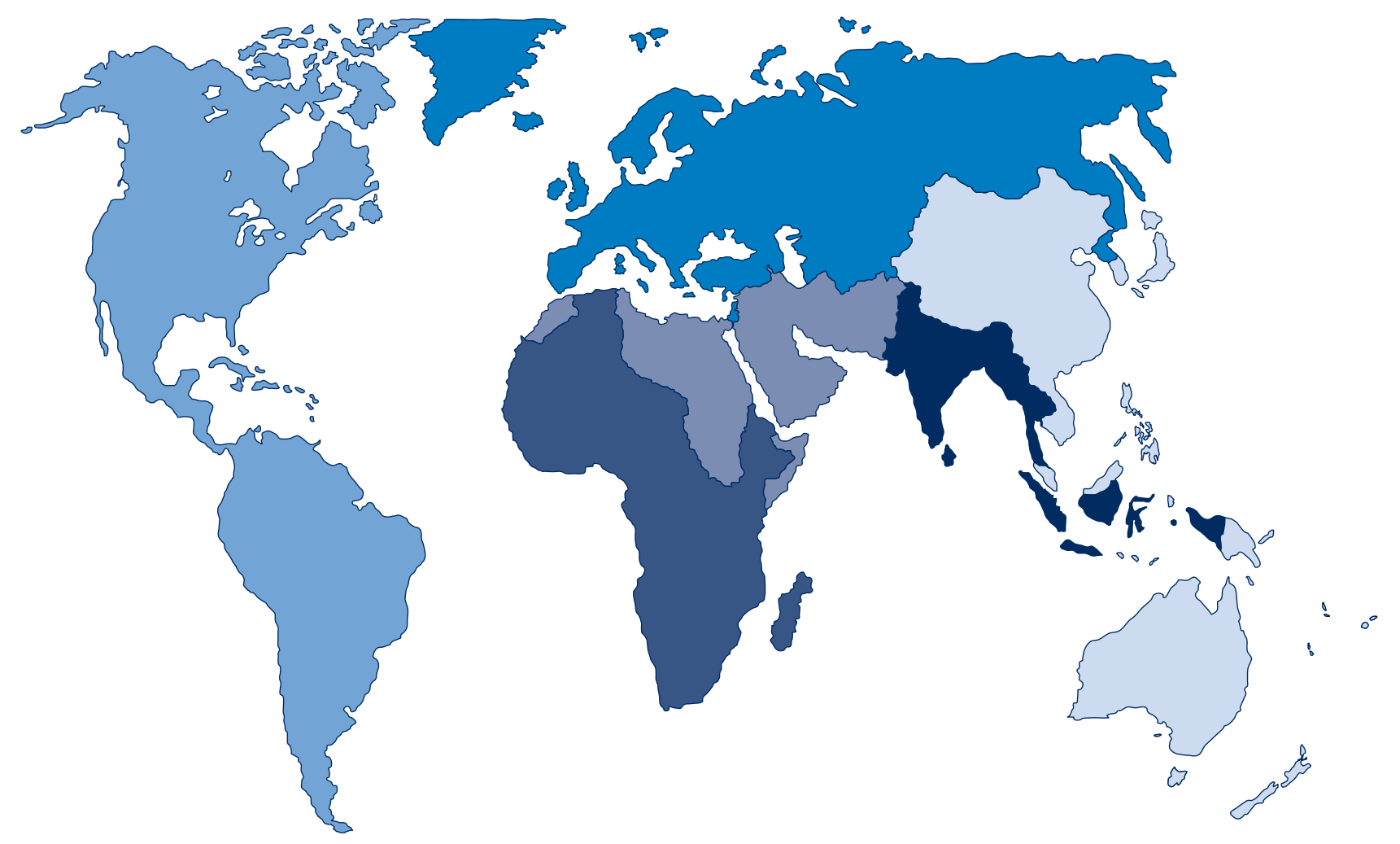

WHO African Region

WHO Region of the Americas

WHO South-East Asia Region

WHO Eastern Mediterranean Region

WHO European Region

WHO Western Pacific Region

Figure 1. World Health Organization regions.

Source: World Health Organization.

these cases. ${ }^{3}$ According to WHO, 84 countries have reported cases of extensively drug-resistant TB (XDRTB). Within these countries, an average of $9 \%$ of MDR-TB cases have XDR-TB. ${ }^{1}$ Eight of the 37 (22\%) countries of the WPR have reported at least one case of XDR-TB. ${ }^{5}$

Particular challenges for TB control in Australia include its proximity to, and relationship with, Papua New Guinea (PNG), which had a TB incidence rate of 346 cases per 100000 population in $2011 .^{1}$ The Torres Strait Protected Zone is an area within the narrow seaway separating Australia and PNG; scattered throughout are over 100 islands ( 22 of which are currently inhabited). People from the area are entitled to free movement between Australia and PNG. Past uncertainty as to the role of different agencies in treating people with TB in this area has resulted in a failure to control TB in the Zone and has provided possible avenues for transmission of MDR-TB to Australia. Significantly, transmission of MDR-TB has been recognised among PNG nationals accessing health care in the Torres Strait Islands of Queensland. From 2004 to 2007, 24 cases of MDR-TB were diagnosed among this group, representing a substantial demand on human and financial resources and highlighting the need for effective, collaborative TB control strategies. ${ }^{2,4,6}$ While improvements in the care of MDR-TB have made it possible to manage the disease in most cases, it requires special multidisciplinary care by expert groups. ${ }^{2,4}$ MDR-TB cases arising in the WPR will continue to have an impact on TB control in Australia in the future. TB services will need to plan to deal with these impacts.

The estimated prevalence of human immunodeficiency virus (HIV) in new TB cases in the WPR was $2.3 \%$ in $2010,{ }^{3}$ with countries ranging from less than $1 \%$ up to $15 \%$. WHO reports that HIV has the potential to reverse the gains of TB control in several parts of the region, particularly in Cambodia, Malaysia, PNG, Viet Nam and areas of China. ${ }^{3}$

Diabetes is associated with an increased risk of progression to active TB disease. People with diabetes have a three times greater risk of developing TB following exposure, a four times greater risk of relapse post-TB treatment and a five times greater risk of death during TB treatment. ${ }^{7}$ In 2011, the estimated prevalence of diabetes in the WPR was $8.5 \%$ for the adult population; this is expected to increase to $10.6 \%$ by $2030 .{ }^{8}$ Within the WPR, Pacific Island countries/territories were reported as having the highest diabetes prevalence rates (15.5\%) globally in 2008 and the largest rise in rates of fasting plasma glucose between 1980 and 2008. ${ }^{9}$ In Palau, Guam, Federated States of 


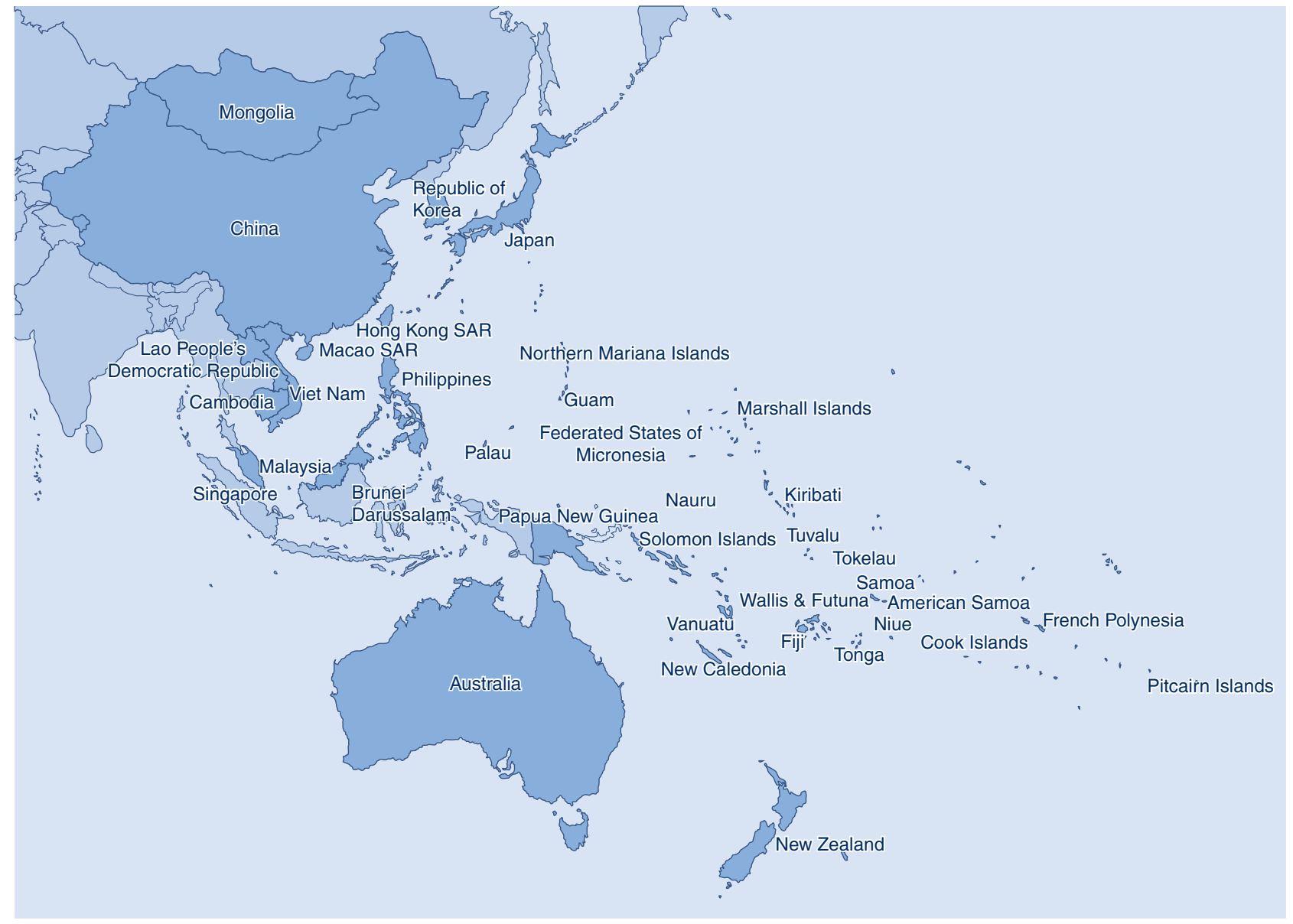

Figure 2. Countries and areas of the World Health Organization Western Pacific Region. Source: World Health Organization.

Micronesia, Republic of Marshall Islands, American Samoa and Commonwealth of Northern Mariana Islands (Figure 2), TB programs are reporting $30-75 \%$ of their caseload as having co-morbid diabetes. ${ }^{10}$ Diabetes is reported to affect $4 \%$ of the Australian population, having more than doubled between 1990 and 2008. ${ }^{11}$ If diabetes prevalence rates continue to increase in Australia, this will probably influence the incidence of TB. Furthermore, increased numbers of people with co-morbid diabetes will lead to increasingly complex case management and greater challenges for TB services.

The Regional Strategy to Stop Tuberculosis in the Western Pacific (2011-2015) was adopted by the Western Pacific Regional Office (WPRO) of WHO in October 2010 (Box 1). WHO data show that the WPR is on track to meet the United Nations Millennium Development Goals to halve the TB prevalence and mortality rates of the year 2000 by $2015 .{ }^{1}$

TB control strategies are implemented by each country in the WPR through their national TB control programs. Regional networks also exist to support these activities and include not only the WPRO, but also the Union Asia Pacific Region (Union APR) and the Secretariat of the
Pacific Community (SPC). These latter networks provide structures through which the WPR can negotiate cooperative activity with neighbouring regions such as the SEAR.

\section{Australia's current role in TB control in the WPR}

Australia provides support for TB control in the WPR via a number of government, non-government and international organisations. Strengthening regional partnerships has long been recognised by Australian TB authorities as an important activity and is made explicit within the national strategy for TB control. ${ }^{2,12}$ This approach also reflects Australia's current diplomatic approach which is "to connect and create partnerships that build and strengthen the global and regional rules-based order and have the capacity to solve shared global problems". ${ }^{13}$ Regional partnerships offer opportunities to advocate for local and regional approaches to TB control, such as adequate resourcing of TB programs; workforce development, education and training; basic and operational research; as well as technical assistance provided through structured programs which service the recipient and provider by offering opportunities to gain and maintain skills. However, strengthening regional TB partnerships has, to date, been primarily a passive and opportunistic response by 


\section{Goal}

To reduce by half the prevalence of and mortality from all forms of TB by 2015 , relative to 2000 levels, in all countries with a high burden of TB by moving towards universal access to diagnosis and treatment of all forms of TB, including smear-negative and multidrug and extensively drug-resistant TB.

\section{Objectives}

1. Promoting universal and equitable access to quality TB diagnosis and treatment for all people

2. Strengthening TB laboratory capacity

3. Scaling up the programmatic management of drug-resistant TB

4. Expanding TB/HIV collaborative activities

5. Strengthening TB program management capacity

Source: World Health Organization. Regional Strategy to Stop Tuberculosis in the Western Pacific 2011-2015.

individuals and organisations within Australia to an expressed need, rather than a structured strategic approach to regional disease control.

The Australian Government is committed to the United Nations Millennium Development Goals that aim to maximise the impact of foreign aid to improve the lives of the poor. TB has long been associated with poverty and those people vulnerable to ill health through socio-economic, biological and environmental factors. ${ }^{14}$ Foreign aid constitutes 2\% ( $\$ 5.2$ billion) of the Federal Budget in 2012-13. Seventy percent of the foreign aid budget in 2015 is to go to the Asia Pacific Region; ${ }^{15}$ of this, approximately $\$ 1.5$ billion will be spent in countries of the WPR. The funded programs support TB control by addressing poverty, improving policing and building stability (PNG, Solomon Islands, Vanuatu, Kiribati, Tuvalu and Nauru); improving access to immunisation, higher education and drinkable water (Kiribati); and improving education and agricultural productivity (Cambodia and Laos). ${ }^{16}$ Of the foreign aid budget in 2012-13, \$70 million is allocated to the Global Fund to Fight AIDS, Tuberculosis and Malaria.

\section{Specific Australian TB promotion and support in the WPR}

The Australian Government has recently endorsed The strategic plan for control of tuberculosis in Australia: 2011-2015. ${ }^{2}$ While this plan outlines a strategy for TB control in Australia, it incorporates a regional approach to disease control and aligns Australian initiatives with those detailed in the WHO's Regional Strategy to Stop Tuberculosis in the Western Pacific 2011-2015. ${ }^{3}$

There are a range of agencies supporting TB control in the WPR. Australia's TB laboratory network, along with those from New Zealand and the United States, provide TB culture and drug susceptibility testing to countries of the WPR, as well as Timor-Leste. These networks also contribute to regional laboratory capacity building through education and training. Research organisations such as the Woolcock Institute of Medical Research, the Centenary Institute, the Burnet Institute, and the Walter and Eliza Hall Institute of Medical Research, as well as various Australian universities, have been investing in TB in the WPR and contributing to increased regional capacity for operational research. International advocacy agencies such as RESULTS (International) Australia actively lobby the Federal Government on regional aid issues, including TB.

Non-government agencies fund TB capacity building projects, such as the partnership between the Australian Respiratory Council (ARC), the Thoracic Society of Australia and New Zealand and the Cambodia AntiTuberculosis Association, combating TB in the villages and factories of Phnom Penh.

The ARC is the Australian constituent member of the International Union Against Tuberculosis and Lung Disease (the Union), the international organisation spearheading global efforts against TB throughout the last century. This relationship affords opportunities for regional dialogue on all aspects of TB control, via the Union APR Council and Scientific Committees. The ARC has been supporting regional education and training activities for clinicians, laboratories, nurses and allied health workers since the 1950s, most recently in partnership with the WPRO, SPC, the Pacific Island Health Officers' Association and the United States Centers for Disease Control and Prevention. Australian TB experts are engaged by countries themselves, the WPRO, the Union APR and SPC to provide technical assistance to TB programs and to participate in regional discussions on TB control, such as the biennial Pacific Stop TB meetings and Union APR Regional Conferences.

WHO, the Union APR and the SPC all struggle to meet the technical needs within the region. The strategic plan for 
control of tuberculosis in Australia: 2011-2015 offers an opportunity for Australia to develop a more deliberate and structured approach to regional engagement for TB control.

\section{TB control in Australia}

As a developed nation and an island continent, Australia has enjoyed low indices for burden of TB disease (mortality, incidence, HIV co-infection, MDR-TB and XDR-TB disease). ${ }^{4}$ The incidence of TB in Australia has remained low over the last 30 years (5-6 cases per 100000 population), ${ }^{4,17}$ however there has been little progress toward TB elimination $\left(<1\right.$ case per million population). ${ }^{1}$ Incidence rates for the Australian-born population have decreased while those for the overseas-born population are increasing. ${ }^{4,17}$ There has been a continual increase in the number and rate of multidrug-resistant cases since 1995 to a rate of $2.9 \%$ of TB cases in $2009(n=31) .{ }^{4,17}$ Almost $95 \%$ of MDR-TB cases are in the overseas-born population. ${ }^{6}$ Regional success in controlling TB impacts on Australia's success in controlling this disease. ${ }^{2,4,6}$ The pathogenesis and transmission of TB make it difficult to achieve elimination within a geographically bound area. ${ }^{4}$ Globalisation and increasing economic and strategic engagement within the region amplifies this effect. Australia is dependent on immigration for population growth and economic development. ${ }^{18}$ Australia's ability to maintain current indices of TB control and progress toward elimination within this environment requires not only a range of national strategies, but also international strategies which contribute to global efforts to combat the disease. Immigration trends need to be considered in the development of strategies for controlling TB in Australia.

The Australian National TB Program requires the Commonwealth, states and territories to work together. The Commonwealth monitors the incidence and prevalence of $\mathrm{TB}$ on a national basis using data from the states and territories. The National TB Advisory Committee provides expert guidance and support to the Commonwealth on issues related to TB control. The states and territories have complementary roles to the Commonwealth, including managing TB services; ensuring close working relationships between public health, laboratories, clinicians and TB services; and conducting research. ${ }^{12}$ The TB programs in the states and territories are very differently structured and each have their own models of care for delivering TB services. Faced with increasing health system rationalisation and focus on acute care delivery and non-communicable diseases, Australian TB programs are increasingly reporting concerns regarding their sustainability and program maintenance. ${ }^{19-22}$ These concerns relate to the ageing workforce, the provision of training and education, service fragmentation, financial resourcing, sustainable drug supply and access to vaccination for at-risk groups.

\section{Australia's future role in TB control in the WPR}

While it has been a considerable achievement to maintain a low TB incidence rate in Australia, progression towards TB elimination, and perhaps ongoing maintenance of current achievements, presents a significant challenge. The maintenance and advancement of TB control in Australia requires: a commitment to TB program funding at national, state and local levels; investment in basic and operational TB research in Australia and the WPR; and financial commitment to support regional collaboration among experts to address local and regional issues and to provide mentoring and technical support to regional partners. Strategic engagement with regional partners provides an opportunity to progress these objectives while also providing opportunities for Australian health workers to increase their knowledge and skills in TB management and to undertake TB research. Advocacy has a role to play in increasing the Australian public's understanding of TB and to mobilise community and public support for enhanced efforts toward TB elimination in Australia and the region.

\section{Conclusion}

The profile of TB in the WPR is reflected in the profile of TB in Australia. Australia's role in the WPR includes a range of capacity building, advocacy and research activities. Increased and strategic engagement within the region offers Australia an opportunity to progress towards TB elimination and to contribute to regional and global TB elimination efforts.

\section{References}

1. World Health Organization. Global tuberculosis report 2012. Geneva: World Health Organization; 2012.

2. National Tuberculosis Advisory Committee (NTAC) of Communicable Disease Network Australia (CDNA). The strategic plan for control of tuberculosis in Australia: 2011-2015. Available at: http://www.health.gov.au/internet/main/ publishing.nsf/Content/cda-cdi3603i.htm (Cited 18 January 2013).

3. World Health Organization. Regional Strategy to Stop Tuberculosis in the Western Pacific 2011-2015. Available at: http://www.wpro.who.int/tb/documents/policy/2010/regional_ strategy/en/index.html (Cited 10 October 2012).

4. Barry C, Waring J, Stapeldon R, Konstantinos A; National Tuberculosis Advisory Committee, for the Communicable Diseases Network Australia. Tuberculosis notifications in Australia, 2008 and 2009. Commun Dis Intell 2012; 36(1): 82-94.

5. World Health Organization. Frequently asked questions - XDRTB. Available at: http://www.who.int/tb/challenges/xdr/faqs/en/ index.html (Cited 20 May 2013).

6. National Tuberculosis Advisory Committee multi-drug resistant tuberculosis: information paper (October 2007). Commun Dis Intell Q Rep 2007; 31(4): 406-9.

7. Baker MA, Harries AD, Jeon CY, Hart JE, Kapur A, Lönnroth K et al. The impact of diabetes on tuberculosis treatment outcomes: a systematic review. BMC Med 2011; 9: 81. doi:10.1186/17417015-9-81 
8. International Diabetes Federation. Global Diabetes Atlas. 5th ed. 2012. Available at: http://www.idf.org/diabetesatlas/5e/ western-pacific (Cited 14 November 2012).

9. Danaei G, Finucane M, Lu Y, Singh GM, Cowan MJ, Paciorek $\mathrm{CJ}$ et al. National, regional, and global trends in fasting plasma glucose and diabetes prevalence since 1980: systematic analysis of health examination surveys and epidemiological studies with 370 country-years and 2.7 million participants. Lancet 2011; 378 (9785): $31-40$.

10. Curry International Tuberculosis Center. CNTC Newsletter Archive - Winter 2011. Standards for TB and Diabetes Developed for Pacific Islanders. Available at: http://www.currytb center.uscf.edu/aboutus/newsarchive/ctnc_news_2011Q1.cfm (Cited 20 October 2012).

11. Australian Institute of Health and Welfare. Diabetes prevalence in Australia: detailed estimates for 2007-08; July 2011. Diabetes Series no 17. Cat no. CVD 56. Canberra: AIHW.

12. National TB Advisory Committee (NTAC) of Communicable Disease Network Australia (CDNA). National Strategic Plan for TB Control in Australia beyond 2000. March 2002. Available at: http://www.health.gov.au/internet/main/ publishing.nsf/Content/cda-pubs-other-tb_plan.htm (Cited 12 September 2012).

13. Rudd K. The rise of the Asia Pacific and the role of creative middle power diplomacy (Speech). 19 May 2011. Available at: http://www.foreignminister.gov.au/speeches/2011/ kr_sp_110519.html (Cited 22 October 2012).

14. World Health Organization. Addressing Poverty in TB Control: Options for National TB Control Programmes. 2005. Available at: http://whqlibdoc.who.int/hq/2005/WHO_HTM_TB_2005. 352.pdf (Cited 12 September 2012).
15. Australian Government. AusAID - Summary of Australia's Overseas Aid Program 2012-13, Budget Highlights. 8 May 2012. Available at: http://www.ausaid.gov.au/Budgets/ Documents/budget-highlights-2012-13.pdf (Cited 22 October 2012)

16. Australian Government. Minister for Foreign Affairs. Aid Budget Statement 2012-13. Canberra. 8 May 2012. Available at: http://www.budget.gov.au/2012-13/content/ministerial_ statements/ausaid/download/ausaid.pdf (Cited 21 October 2012)

17. Oliver G. Tuberculosis notifications in Australia, 1994. Commun Dis Intell 1996; 20(5): 108-15.

18. Australian Bureau of Statistics. Cultural Diversity in Australia Reflecting a Nation: Stories from the 2011 Census, 2012-2013. 21 March 2012. ABS Cat. No. 2071.0. Available at: http:// www.abs.gov.au/ausstats/abs@.nsf/Lookup/2071.0main+ features902012-2013 (Cited 12 October 2012).

19. Moore T. Absolute disaster: TB centre faces closure. Brisbane Times. 1 August 2012.

20. Banner P (Session Chair). Key initiatives, challenges and activities for the respective Jurisdictional Programs. Australian TB Conference, Sydney, 1-2 November 2012.

21. Shaw K. Regional issues and challenges and the potential impact on our Australian TB Program. Australian TB Conference, Sydney, 1-2 November 2012.

22. Moore T. Campbell Newman hear our cry: nurses rally against TB changes. Brisbane Times. 8 August 2012. 